\title{
Intérêt de la caractérisation biochimique pour l'évaluation de la proportion de matière organique stable après décomposition dans le sol et la classification des produits organominéraux
}

\author{
D Robin \\ Centre de recherches SCPA, F-68700 Aspach-le-Bas, France
}

(Reçu le 25 septembre 1996; accepté le 20 février 1997)

\begin{abstract}
Summary - Usefulness of organic profiles for evaluating the stable organic matter fraction produced during decomposition in soil and the classification of organic manures. The organic compositions of 61 organic manures currently used in agriculture were analysed and eight of them incubated in soil under controlled conditions. These organic analyses were compared statistically with the total $\mathrm{C}$ and $\mathrm{N}$ concentrations. The organic composition of a manure was neither correlated with its $\mathrm{C}$ and $\mathrm{N}$ contents, nor its $\mathrm{C} / \mathrm{N}$ ratio. Four groups of products: fertilizers, organic manures, raw materials and products with a high mineral nutrient content, were defined according to their organic profiles and their agronomic properties and checked by principal component and factor analysis. There was a general correlation between the carbon remaining in the soil and the organic composition of the organic manures. This model provides a consistent evaluation of the stable organic matter supplied to the soil after decomposition of organic manures whose organic profils have been determined and also takes into account the influence of the mineral fraction on humification.
\end{abstract}

organic manures / classification / organic profiles / stability / C/N ratio / mineral fraction

Résumé - La détermination des fractions biochimiques de 61 produits organominéraux a été réalisée ainsi que des mesures respirométriques pour huit produits de ce panel au cours d'une incubation en conditions contrôlées. Ces analyses biochimiques ont été comparées statistiquement avec les teneurs en $\mathrm{C}$ et $\mathrm{N}$ totaux. Les résultats montrent que la constitution biochimique d'un produit n'est pas corrélée à sa teneur en carbone et azote, ni à son rapport $\mathrm{C} / \mathrm{N}$. Différents groupes de produits, suivant leur composition biochimique et leurs propriétés agronomiques, ont été constitués et validés par analyse en composantes principales et analyse factorielle discriminante. Une relation entre taux de carbone restant dans le sol et composition biochimique des produits a été établie. Cette modélisation aboutit à une estimation du potentiel humique des produits organominéraux testés à partir de leur constitution biochimique, en incluant l'effet de la fraction minérale dans le processus d'humification.

matière organique / classification / analyse biochimique / stabilité / rapport $\mathrm{C} / \mathrm{N}$ / fraction minérale

* Correspondance et tirés à part.

Tél : 0389487013 ; fax : 0389487903 ; courriel : scpa@calva.com.fr 


\section{INTRODUCTION}

L'utilisation en agriculture des produits organominéraux pour améliorer le rendement et la qualité des productions agricoles existe depuis toujours (Boulaine, 1995). Pour une utilisation rationnelle de ces produits, il est nécessaire de connaître leurs propriétés agronomiques : effet amendant et/ou fertilisant. Outre les éléments nutritifs apportés ou libérés, certains produits organominéraux apportent des quantités importantes de composés organiques qui, après transformation dans le sol, reconstituent le stock humique du sol. Le rapport $\mathrm{C} / \mathrm{N}$ est un indicateur du potentiel humique des résidus organiques classiques (résidus végétaux et déchets animaux), c'est-à-dire de la proportion d'humus stable qui se forme dans le sol après décomposition de la matière organique. Il est admis que, plus le rapport $\mathrm{C} / \mathrm{N}$ d'un produit est élevé, plus il se dégrade lentement dans le sol et plus il fournit de l'humus stable (Waksman, 1924 ; Jensen, 1929; Allison, 1955 ; Fog, 1988). La décomposition lente de ces composés peut être attribuée dans la plupart des cas à une composition de ces produits en macromolécules fortement polymérisées difficiles à décomposer (Swift et al, 1978 ; Monties, 1980) et/ou à une limitation de la décomposition liée à la faible teneur en azote des produits (Fog, 1988 ; Robin, 1994 ; Recous et al, 1995). Ce rapport $\mathrm{C} / \mathrm{N}$ est un indicateur fréquemment utilisé dans la pratique pour préciser l'utilisation d'un produit organique inconnu comme par exemple dans le Code de bonne pratique agricole (Corpen, 1991). Cependant, plusieurs études ont montré les limites de l'utilisation systématique de ce paramètre par la mise en évidence de vitesses de décomposition rapide pour des produits à $\mathrm{C} / \mathrm{N}$ élevés ou une décomposition lente pour des produits ayant un rapport $\mathrm{C} / \mathrm{N}$ faible (Mary, 1987; Lineres et Djakovitch, 1993 ; Mary et al, 1993).

De nombreux travaux se sont intéressés aux conséquences des apports de produits organominéraux sur l'évolution de la teneur en matière organique dans le sol. Parmi ces expérimentations, les travaux de Hénin et Dupuis (1945) proposent un modèle monocompartimental de l'évolution de la matière organique du sol reposant sur les mesures de $\mathrm{C}$ total du sol et sur la connaissance de deux coefficients nommés coefficient isohumique $\mathrm{k} 1$ et coefficient de minéralisation $\mathrm{k} 2$. Le coefficient isohumique $\mathrm{k} 1$ définit le rendement de transformation en $\mathrm{C}$ stable de l'apport organique et le coefficient $\mathrm{k} 2$ le taux de minéralisation de la matière organique endogène du sol. Bien qu'il existe de nombreux modèles pour décrire l'évolu- tion du carbone organique du sol (Hénin et al, 1959 ; Jenkinson et Rayner, 1977 ; Delphin et Conesa, 1979), le coefficient $\mathrm{kl}$ est un paramètre souvent utilisé dans la pratique pour définir le potentiel humique, c'est à dire la proportion de $\mathrm{C}$ stable après décomposition dans le sol d'un produit organique. Cependant, l'estimation de ce potentiel reste délicate. Des expérimentations de longue durée en plein champ (Morel et al, 1956; Morel, 1968 ; Boiffin et al, 1986) ou des mesures respirométriques sont nécessaires pour déterminer ce coefficient. Ces deux techniques présentent l'inconvénient d'être longues et coûteuses et quelques lacunes d'ordre méthodologique sont rencontrées pour les essais de longues durées (Djakovitch, 1988).

Les travaux de Djakovitch (1988) et Lineres et Djakovitch (1993) proposent une méthode d'estimation de ce coefficient par l'analyse biochimique de la partie organique suivant la méthode de fractionnement de Van Soest et Wine (1963). En fonction de sa composition biochimique en fraction soluble, hémicelluloses, cellulose et lignine, ces auteurs proposent une formule de calcul du coefficient isohumique $\mathrm{k} 1$. Cette technique de laboratoire, rapide, reproductible et peu coûteuse peut être l'outil recherché pour estimer le potentiel humique d'un produit organominéral inconnu. Cependant, l'ajustement du coefficient isohumique réalisé par Djakovitch (1988) a été réalisé à partir de mesures respirométriques de quelques produits organiques pauvres en matières minérales incubés dans un sol. Or, une fraction minérale plus ou moins importante est susceptible de modifier le processus de décomposition et d'humification d'un produit organique. En effet, l'influence des minéraux du sol : teneur en argile, niveau d'agrégation, etc, sur la décomposition et la protection de la matière organique est connue (Martin et al, 1976; Van Veen et Paul, 1981; Hassink, 1994). Bien qu'aucun élément bibliographique n'en fasse état, il est possible que, pour des produits riches en matières minérales, les minéraux constitutifs du produit aient un rôle non négligeable sur ce mécanisme de «protection physique» semblable à celui des minéraux du sol.

En vue d'une estimation du potentiel humique des produits organominéraux, une étude de la composition biochimique et des teneurs en carbone et en azote de soixante et un produits organominéraux de provenance et d'usage agricole différents a été réalisée. Simultanément, des mesures respirométriques ont été faites au cours de la décomposition dans le sol en conditions contrôlées de huit produits du panel étudié. Ce travail a pour objet de tester l'éventuel effet de la fraction 
minérale du produit sur le processus d'humification, de l'intégrer dans une éventuelle estimation du potentiel humique et de classer les produits organominéraux en termes d'usage agricole en fonction de leur composition biochimique. Les potentiels humiques calculés suivant la formule proposée dans ce travail sont discutés ainsi que les améliorations possibles de cette estimation pour les différents types de produits organominéraux testés.

\section{MATÉRIELS ET MÉTHODES}

\section{Produits organiques}

Soixante et un échantillons de produits organominéraux, rassemblés entre 1994 et 1996, ont été caractérisés (tableau I). Ces produits représentent un panel large des substances organominérales utilisables en agriculture : engrais et amendements organiques commerciaux, boues de station d'épuration, composts d'origine végétale ou mixte (boues ou ordures ménagères + végétaux), fumier frais ou composté de différentes origines, résidus de culture, marc de raisins, matières premières pour la confection de compost (tourteau de cacao et de café, pulpes de raisins) ainsi que des engrais organiques (guano d'oiseaux, farines de plumes hydrolysées). Après échantillonnage, chaque produit a été séché à $40^{\circ} \mathrm{C}$ jusqu'à stabilisation du poids puis broyé à $1 \mathrm{~mm}$. Cette température modérée de séchage permet de limiter les pertes d'azote et d'éviter la dénaturation des molécules organiques, notamment en limitant les réactions de condensations de type Maillard entre glucides et protéines. Ces réactions sont d'autant plus fréquentes que la température et la teneur en eau sont élevées et que la teneur en $\mathrm{N}$ est importante (Thomas et Amstrong, 1949 ; Van Soest, 1949).

\section{Caractérisation biochimique par la méthode de Van Soest et Wine (1963)}

L'analyse biochimique a été réalisée suivant la méthode de Van Soest et Wine (1963) sur $1 \mathrm{~g}$ de produit sec. Chaque fraction biochimique est solubilisée par un réactif approprié (fig 1 ) et le résidu restant est séché à $40^{\circ} \mathrm{C}$ jusqu'à stabilisation du poids puis pesé. À chaque étape de solubilisation, la teneur en matières minérales est mesurée (par calcination à $500{ }^{\circ} \mathrm{C}$ pendant $5 \mathrm{~h}$ ) sur le résidu obtenu pour intégrer une éventuelle variation essentiellement due à une solubilisation partielle des matières minérales dans le solvant utilisé. La solubilisation de la fraction cellulosique est faite par attaque à l'acide sulfurique $72 \%$ à froid suivant la technique originale de Van Soest et Wine (1963). Cette technique a été préférée à la solubilisation à chaud par action successive de $\mathrm{H}_{2} \mathrm{SO}_{4} 0,255 \mathrm{~N}$ et $\mathrm{NaOH} 0,313 \mathrm{~N}$ utilisée par Djakovitch (1988). En effet, des échantillons de cellulose pure commerciale ne sont pas com-
Tableau I. Liste des produits organominéraux testés.

\begin{tabular}{|c|c|}
\hline Types de produits & $n^{\circ}$ des échantillons testés \\
\hline Boues de stations urbaines & $\begin{array}{l}1-11-12-13-14-15-45- \\
46-57-58-59\end{array}$ \\
\hline Compost d'origine végétale & $\begin{array}{l}2-40-41-47-48-49-51- \\
52-54-55-56\end{array}$ \\
\hline $\begin{array}{l}\text { Amendements organiques } \\
\text { commerciaux }\end{array}$ & $\begin{array}{l}3-5-6-16-17-18-20-23- \\
25-26-31-35-36-37-38-39\end{array}$ \\
\hline $\begin{array}{l}\text { Engrais organiques } \\
\text { commerciaux }\end{array}$ & $4-19-21-22-24$ \\
\hline \multicolumn{2}{|l|}{ Fumiers de différentes origines } \\
\hline Champignonnière & 7 \\
\hline Bovin frais & 44 \\
\hline Bovin composté & 42 \\
\hline Cheval composté & 43 \\
\hline Bergerie frais & 29 \\
\hline Bergerie composté & 30 \\
\hline Marc de raisins & 8 \\
\hline \multicolumn{2}{|l|}{ Résidus de culture } \\
\hline Maïs & 9 \\
\hline Blé & 10 \\
\hline \multicolumn{2}{|l|}{ Tourteaux végétaux } \\
\hline Cacao & 27 \\
\hline Café & 34 \\
\hline Guano d'oiseaux & 28 \\
\hline Pulpe de raisins & 32 \\
\hline Farine de plumes hydrolysées & 33 \\
\hline Compost d'ordures ménagères & $50-53$ \\
\hline $\begin{array}{l}\text { Compost d'origine mixte } \\
\text { (boues ou ordures ménagères } \\
+ \text { végétaux) }\end{array}$ & $60-61$ \\
\hline
\end{tabular}

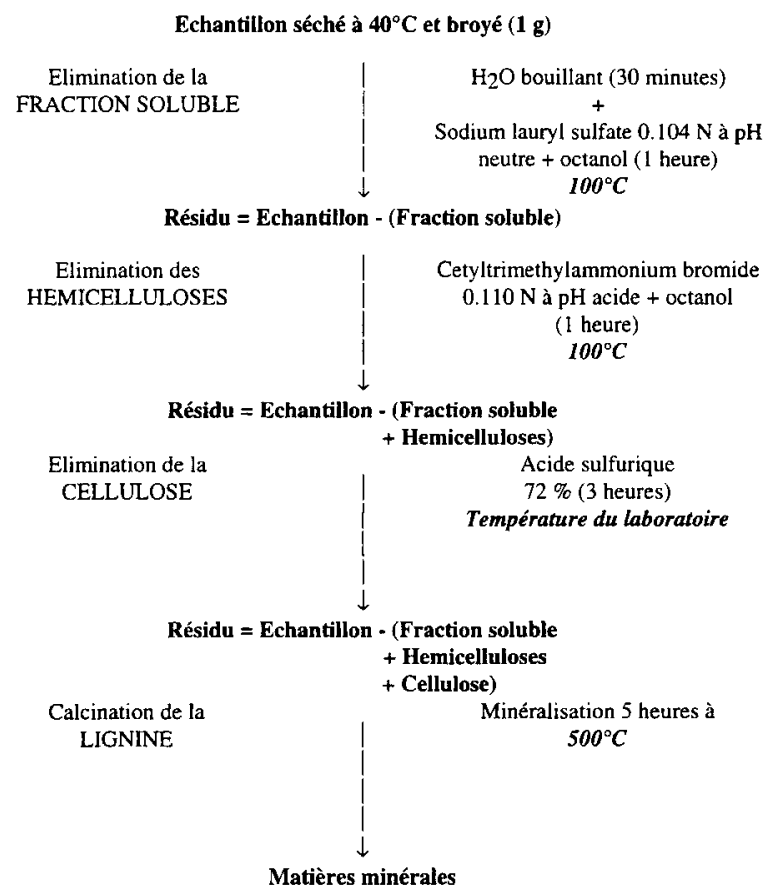

Fig 1. Technique de fractionnement biochimique de la matière organique suivant la méthode de Van Soest et Wine (1963). 
plètement solubilisés par la méthode utilisée par Djakovitch (1988) alors qu'une dissolution complète est obtenue par l'acide sulfurique à froid selon la technique originale. Les teneurs en $\mathrm{C}$ et $\mathrm{N}$ total sont déterminées après décarbonatation par combustion sèche de type Dumas à l'aide d'un analyseur élémentaire de $\mathrm{C}$ et N (Leco CNS 2000).

\section{Incubations en conditions contrôlées des produits organiques}

Le choix des produits a été fait suivant l'analyse biochimique dans le but de tester des produits facilement, moyennement et peu dégradables dans le sol et pour tester différentes teneurs en matières minérales. Deux engrais organiques se décomposant a priori rapidement dans le sol ( $\mathrm{n}^{\circ} 11$ et 24$)$, deux amendements organiques a priori stables ( $n^{\circ} 30$ et 31 ), trois produits riches en matières minérales $\left(n^{\circ} 4,13\right.$ et 17$)$ et un produit riche en fraction soluble et hémicelluloses $\left(n^{\circ} 16\right)$ ont été retenus pour cette étude. La teneur en matières minérales de ce panel varie de $19 \%\left(\mathrm{n}^{\circ} 16\right)$ à $81 \%\left(\mathrm{n}^{\circ} 13\right)$.

Le sol utilisé pour l'incubation a été prélevé plusieurs semaines avant la mise en place de l'essai dans l'horizon $0-10 \mathrm{~cm}$ d'une parcelle expérimentale du Centre de recherches d'Aspach-le-Bas (France). Le sol utilisé, un sol brun lessivé décalcifié (teneur en $\mathrm{CaCO}_{3}$ nulle) développé sur loess de la plaine d'Alsace (Néoluvisol), possède une texture limoneuse: $17 \%$ argile, $66 \%$ limon, $17 \%$ sable avec $1,1 \%$ de $\mathrm{C}$ organique, $0,10 \%$ de $\mathrm{N}$ total et un $\mathrm{pH}$ eau de 6,4 . Le sol a été conditionné suivant la technique décrite par Recous et al (1995). Il a été séché pendant $4 \mathrm{j}$ à température ambiante pour atteindre une humidité pondérale de $15 \%$ puis tamisé pour obtenir des agrégats compris entre 2 et $3,15 \mathrm{~mm}$. Tous les cailloux et particules organiques visibles ont été retirés manuellement. L'humidité du sol est ensuite ajustée à une humidité pondérale de $16 \%$ puis le sol est stocké à $4{ }^{\circ} \mathrm{C}$ avant utilisation.

Chaque échantillon élémentaire est constitué de $29 \mathrm{~g}$ de terre à $16 \%$ d'humidité, soit $25 \mathrm{~g}$ de terre sèche, et de $100 \mathrm{mg}$ de produit organique séché qui sont mélangés aux agrégats de sol à l'aide d'une spatule. Cet apport organique est équivalent à une incorporation de $4 \mathrm{~g} \mathrm{~kg}^{-1}$ de sol sec ou encore $8 \mathrm{tha}^{-1}$ de matière sèche incorporées sur $15 \mathrm{~cm}$ de profondeur. Pour éviter une limitation de la décomposition par la disponibilité en azote minéral (Robin, 1994 ; Recous et al, 1995), un apport d'azote minéral équivalent à $100 \mathrm{mg} \mathrm{N} \mathrm{kg}^{-1}$ de sol sec a été réalisé. Pour chaque échantillon, l'apport d'azote sous forme de $\mathrm{KNO}_{3}$ a été réalisé à la surface de l'échantillon, sans mélange, à l'aide d'une micropipette de précision. La solution d'azote est apportée dans un volume de $1 \mathrm{ml}$ ce qui amène l'humidité pondérale à une valeur finale de $20 \%$. Cette humidité correspond à un potentiel hydrique de -30 à $-50 \mathrm{kPa}$, potentiel favorable à la décomposition (Sommers et al, 1981 ) et auquel les agrégats restent insaturés.

L'échantillon est ensuite pesé puis placé dans un bocal étanche de $1 \mathrm{~L}$. Un pilulier d'eau est ajouté pour limiter les pertes d'eau. Pour chaque traitement, un bécher contenant $10 \mathrm{~mL}$ de $\mathrm{NaOH} 0,25 \mathrm{~N}$ est placé dans le bocal pour piéger le $\mathrm{CO}_{2}$ dégagé. Les bocaux sont placés à l'obscurité dans une pièce climatisée dont la température est maintenue à $20 \pm 1{ }^{\circ} \mathrm{C}$. Un traitement sol seul a été réalisé pour mesurer la minéralisation du carbone endogène du sol. Trois répétitions par traitement (sol + produit et sol seul) ont été réalisées.

À chaque mesure, les béchers de $\mathrm{NaOH}$ sont changés, les bocaux aérés et l'humidité des échantillons réajustée. Les mesures ont été réalisées après 0,$7 ; 1,7$; 2,$7 ; 4,8 ; 6,9 ; 9,9 ; 12,9 ; 15,9 ; 19,6 ; 26,0$ et $40,0 \mathrm{j}$ d'incubation à $20^{\circ} \mathrm{C}$. Le $\mathrm{CO}_{2}$ piégé par la soude est précipité par du $\mathrm{BaCl}_{2}$ à $10 \%$ sous forme de carbonate de baryum. L'excès de $\mathrm{NaOH}$ est titré par du $\mathrm{HCl} 0,25 \mathrm{~N}$ à l'aide d'un titrateur couplé à un $\mathrm{pH}$ mètre.

\section{RÉSULTATS}

\section{Caractérisation analytique des produits et classification statistique}

\section{Analyses chimiques et biochimiques}

L'annexe 1 présente les résultats des analyses pour les 61 produits testés et la figure 2 présente la répartition des effectifs en sept classes pour chaque paramètre mesuré. La répartition des effectifs suggère, pour la fraction soluble, l'azote total et le rapport $\mathrm{C} / \mathrm{N}$, une distribution unimodale malgré un effectif important pour la classe supérieure. Pour le $\mathrm{C}$ total, l'histogramme des fréquences suggère une distribution bimodale : entre 20 et $25 \%$ de $\mathrm{C}$ total d'une part et 35 et $40 \%$ d'autre part. On note également un nombre important de produits (17 produits sur 61) ayant une teneur en lignine supérieure à $28 \%$ ainsi que 21 produits sur 61 testés possédant une teneur en matières minérales supérieure à $50 \%$. Le rapport $\mathrm{C} / \mathrm{N}$ des produits testés varie de 1,4 à 83,8 avec 28 produits dont le rapport $\mathrm{C} / \mathrm{N}$ est compris entre 10 et 15 .

\section{Corrélations entre les paramètres étudiés}

Les différentes fractions biochimiques et la fraction minérale mesurée par la méthode Van Soest et Wine (1963) ne sont pas des paramètres techniquement indépendants. En effet, ils sont obtenus par une seule et même technique qui procède par épuisement. Le rapport $\mathrm{C} / \mathrm{N}$ est évidemment lié à la teneur en $\mathrm{C}$ et $\mathrm{N}$ total. Cependant, d'un point de vue statistique, il est tout à fait possible d'étudier la corrélation entre les teneurs en $\mathrm{C}$ et $\mathrm{N}$ et le rapport $\mathrm{C} / \mathrm{N}$ d'une part et les teneurs de chaque fraction biochimique d'autre part. De la même manière, les corrélations entre teneur en matières 
minérales d'une part et les teneurs en $\mathrm{C}$ et $\mathrm{N}$ ainsi que le rapport $\mathrm{C} / \mathrm{N}$ d'autre part peuvent être estimées.

Le tableau II présente les différentes corrélations (coefficient $r$ ) étudiées entre les différents paramètres techniquement non liés. Les résultats montrent la non corrélation entre les fractions biochimiques d'une part et les teneurs en $\mathrm{C}$ et le rapport $\mathrm{C} / \mathrm{N}$ d'autre part. Ceci montre le complément d'information apporté par cette caractérisation
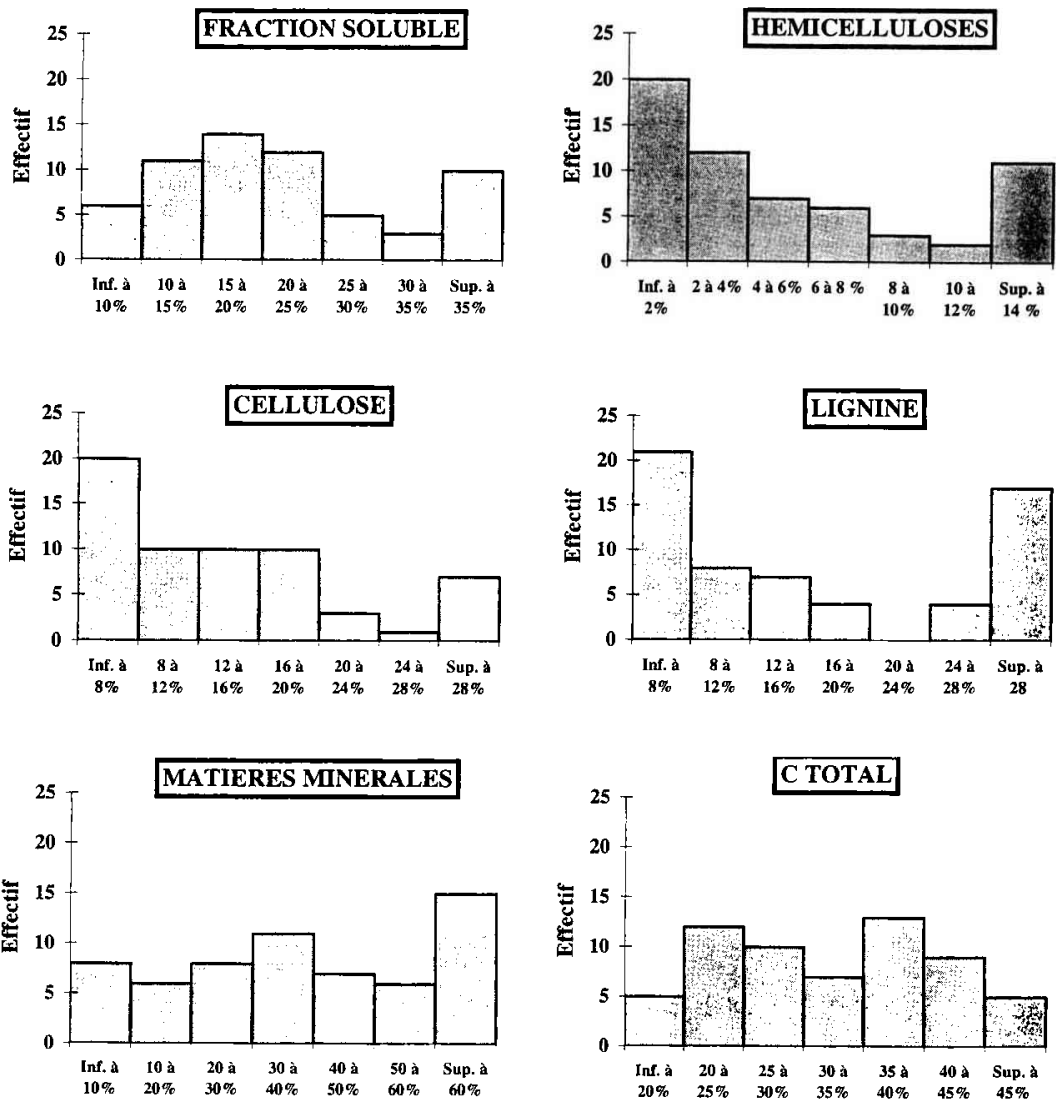

Fig 2. Histogrammes des effectifs pour les différents paramètres mesurés : teneurs en fraction soluble, hémicelluloses, cellulose, lignine, matières minérales, $\mathrm{C}$ et $\mathrm{N}$ total et rapport $\mathrm{C} / \mathrm{N}$.
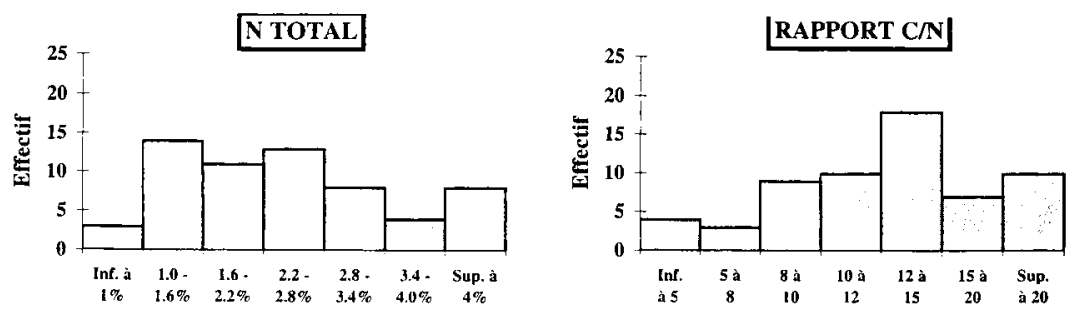

Tableau II. Matrice des corrélations (coefficient $r$ ) entre les teneurs en fraction soluble, hémicelluloses, cellulose, lignine, $\mathrm{C}$ et $\mathrm{N}$ total, matières minérales et rapport $\mathrm{C} / \mathrm{N}$.

\begin{tabular}{|c|c|c|c|c|c|c|c|c|}
\hline & $\begin{array}{l}\text { Fraction } \\
\text { soluble }\end{array}$ & $\begin{array}{c}\text { Hémi- } \\
\text { celluloses }\end{array}$ & Cellulose & Lignine & $\begin{array}{l}\% C \\
\text { total }\end{array}$ & $\begin{array}{l}\% N \\
\text { total }\end{array}$ & $\begin{array}{l}\text { Matières } \\
\text { minérales }\end{array}$ & $\begin{array}{c}\text { Rapport } \\
C / N\end{array}$ \\
\hline Fraction soluble & 1,00 & & & & & & & \\
\hline Hémicelluloses & - & 1,00 & & & & & & \\
\hline Cellulose & - & - & 1,00 & & & & & \\
\hline Lignine & - & - & - & 1,00 & & & & \\
\hline$\%$ C total & 0,05 & 0,42 & 0,67 & 0,56 & 1,00 & & & \\
\hline$\% \mathrm{~N}$ total & 0,54 & 0,18 & -0.07 & $-0,04$ & 0,14 & 1,00 & & \\
\hline Matières minérales & - & - & - & - & $-0,91^{\mathrm{a}}$ & 0,32 & 1,00 & \\
\hline Rapport C/N & 0,35 & 0,44 & 0,62 & 0,00 & - & - & 0,33 & 1,00 \\
\hline
\end{tabular}

a Significatif au seuil de $5 \%$. 
biochimique par rapport aux analyses de $\mathrm{C}$ et $\mathrm{N}$ total classiquement effectuées sur les produits organominéraux. Il existe une corrélation statistiquement significative $(r=-0.91)$ entre la teneur en $\mathrm{C}$ total et la teneur en matières minérales. Cette liaison entre ces deux paramètres semble logique car, plus un produit possède une grande fraction organique essentiellement composée de carbone, plus sa partie minérale est faible.

\section{Détermination de groupes de produits organominéraux à comportement agronomique équivalent}

L'analyse des données en composantes principales (ACP) permet de visualiser des groupes d'individus statistiquement proches. Par diagonalisation, l'ACP représente chaque produit dans un plan constitué de deux axes. L'analyse réalisée sur la matrice de corrélation permet une représentation qui explique $67 \%$ de la variation totale : $38 \%$ pour l'axe des abscisses et $29 \%$ pour l'axe des

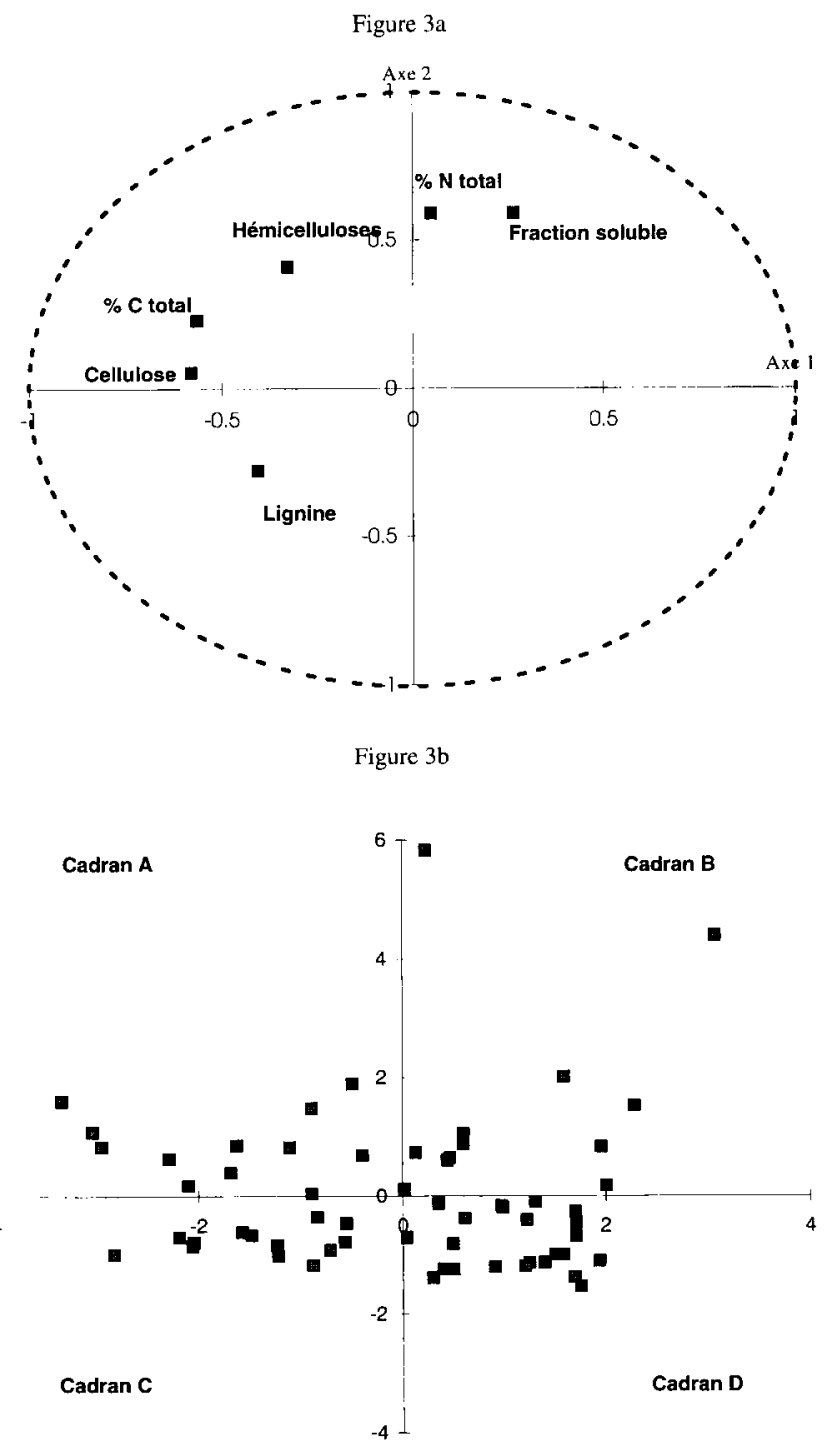

ordonnées. Les axes suivants représentent respectivement 19,8 et $5 \%$ de la variation totale. L'axe des abscisses est principalement expliqué par la teneur en cellulose et en $\mathrm{C}$ total $(r$ respectivement de 0,88 et 0,85 ) et l'axe des ordonnées par les teneurs en $\mathrm{N}$ total et fraction soluble ( $r$ respectivement de 0,77 et 0,77 ). La figure 3 a représente le cercle de corrélation des paramètres suivants: teneurs en fraction soluble, hémicelluloses, cellulose, lignine et en $\mathrm{C}$ et $\mathrm{N}$ total et la figure $3 \mathrm{~b}$ la projection des différents individus.

A priori, on peut définir quatre groupes correspondant à chaque cadran de la représentation graphique. On distingue ainsi un groupe de points situés dans le cadran B. D'un point de vue agronomique, ces produits, riches en fraction soluble et $\mathrm{N}$ total, sont plutôt des composés labiles. Ils sont utilisés comme engrais organiques et se décomposent rapidement dans le sol en libérant des éléments minéraux, notamment de l'azote. On trouve, dans ce cadran $B$, quelques boues de stations urbaines $\left(\mathrm{n}^{\circ} 11,12,14,46,58\right.$ et 59$)$, des engrais
Fig 3. Cercle de corrélation des teneurs en fraction soluble, hémicelluloses, cellulose, lignine et en $\mathrm{C}$ et $\mathrm{N}$ total (a) et projection des différents individus étudiés par analyse en composantes principales (b). 
organiques commerciaux $\left(\mathrm{n}^{\circ} 19,22\right.$ et 24$)$, le guano d'oiseaux $\left(\mathrm{n}^{\circ} 28\right)$, la farine de plumes hydrolysées $\left(n^{\circ} 33\right)$ et un amendement organique commercial $\left(n^{\circ} 6\right)$ possédant une forte teneur en azote $(6,73 \%$ de $\mathrm{N}$ total). Excepté le numéro 6 , ces produits sont utilisés comme engrais organiques en agriculture.

Les produits riches en hémicelluloses, en cellulose ou en lignine sont des composés organiques qui se décomposent plus ou moins lentement et qui apportent des quantités variables de $\mathrm{C}$ organique stable au sol après décomposition: effet amendant plus ou moins marqué. Ces produits se retrouvent dans les cadrans $A$ et $C$. Deux composts d'origine végétale ( ${ }^{\circ} 2$ et 49 ), la plupart des amendements organiques commerciaux $\left(\mathrm{n}^{\circ} 3,16\right.$, $18,20,23,31,35,36,37,38$ et 39 ), un compost mixte de boues et de végétaux $\left(\mathrm{n}^{\circ} 60\right)$, quelques fumiers $\left(\mathrm{n}^{\circ} 29,30,43\right.$ et 44$)$ sont localisés dans ces deux cadrans. On retrouve également les marcs et pulpes de raisins ( $\mathrm{n}^{\circ} 8$ et 32 ), les tiges de blé et de maiis ( $\mathrm{n}^{\circ} 9$ et 10 ) ainsi que les tourteaux de cacao et de café ( ${ }^{\circ} 27$ et 34 ). Cette catégorie de produits (pulpes de raisins, résidus végétaux ou tourteaux) est souvent utilisée comme matière première pour fabriquer, par compostage, des produits amendants de bonne qualité. D'un point de vue agronomique, il est nécessaire de distinguer ces matières premières des amendements organiques vrais en raison de leurs propriétés amendantes différentes. Il est important de signaler que certains amendements commerciaux $\left(n^{\circ} 16,18\right.$, 20,31 et 34 ) ont une composition biochimique plus proche de ces matières premières que celle des amendements vrais. Les matières premières et les produits ayant un profil biochimique semblable se situent autour du vecteur propre des hémicelluloses (cadran A) alors que les amendements vrais sont localisés dans le cadran $\mathrm{C}$.

On définit enfin un nuage de points situés dans le cadran D qui se caractérise par une faible teneur en carbone. Ces produits sont riches en matières minérales et, en raison de leur pauvreté en carbone, ne peuvent pas être utilisés comme amendements organiques. Leurs propriétés fertilisantes restent cependant à définir et varient en fonction de la nature des produits. Dans ce groupe se situent des boues de stations urbaines $\left(\mathrm{n}^{\circ} 1,13\right.$, $15,45,47$ et 57 ), des amendements organiques commerciaux $\left(\mathrm{n}^{\circ} 5,17,25\right.$ et 26$)$, la plupart des composts végétaux $\left(\mathrm{n}^{\circ} 40,41,47,48,51,52,54\right.$, 55 et 56), deux engrais organiques ( $\mathrm{n}^{\circ} 4$ et 21 ), deux fumiers $\left(\mathrm{n}^{\circ} 7\right.$ et 42 ), les deux composts d'ordures ménagères $\left(\mathrm{n}^{\circ} 50\right.$ et 53 ) et un compost mixte $\left(\mathrm{n}^{\circ} 61\right)$.
L'ACP distingue donc a priori quatre groupes différents :

- Groupe I. Produits riches en fraction soluble, utilisés comme engrais organiques, dont la teneur en fraction soluble est supérieure ou égale à $30 \%$ de la matière sèche.

- Groupe II. Produits riches en cellulose et en lignine utilisés comme amendement organique. D'un point de vue pratique, la somme des teneurs en cellulose et lignine est supérieure ou égale à $65 \%$ de la matière organique pour tous ces produits.

- Groupe III. Produits dont la somme des teneurs en fraction soluble et hémicelluloses est supérieure ou égale à $45 \%$ de la matière organique. Ce groupe comprend les matières premières utilisées pour fabriquer les amendements ainsi que quelques amendements commerciaux ou végétaux ayant le même type de profil biochimique que ces matières premières.

- Groupe IV. Produits dont la teneur en matières minérales est supérieure à $40 \%$ de la matière sèche. Ces produits, en raison de leur pauvreté en carbone, ne peuvent être utilisés comme des amendements de qualité mais plutôt comme des engrais organiques dont la fourniture en éléments minéraux reste à définir.

\section{Validation des groupes de produits organominéraux par analyse factorielle discriminante}

L'analyse factorielle discriminante (AFD) permet de vérifier statistiquement l'appartenance d'individus à différents groupes définis a priori. Ce traitement statistique confirme les quatre groupes de produits définis précédemment.

Les paramètres statistiques, calculés pour chaque variable et pour les deux axes définis au cours de la diagonalisation, montrent l'intérêt de cette validation des groupes par analyse factorielle discriminante (tableau III). En effet, la valeur du Pseudo $F$ pour l'axe 1 est très supérieure à la valeur la plus forte du $\mathrm{T}^{2}$ de Hotelling des différentes variables. Ceci confirme la pertinence de cette vérification statistique.

L'analyse discriminante, par calcul de la distance entre les individus et le centre de gravité de chaque groupe, confirme le classement dans les quatre groupes de $83,6 \%$ des produits testés, soit 53 produits sur 61 (tableau IV). Huit produits ont changé de groupe. L'amendement organique $n^{\circ} 6$, initialement classé dans le groupe des engrais organiques, rejoint le groupe des amendements en 
Tableau III. Statistiques calculées pour les différents paramètres et pour les deux axes calculés au cours de l'analyse factorielle discriminante.

\begin{tabular}{ccccccc}
\hline Variable & Fraction soluble & Hémi-celluloses & Cellulose & Lignine & C total & N total \\
\hline $\mathrm{F}\left(\mathrm{T}^{2}\right.$ de Hotelling) & 21,91 & 10,38 & 17,45 & 17,70 & 40,93 & 7,18 \\
Probabilité (\%) & 0,00 & 0,00 & 0,00 & 0,00 & 0,00 & 0,04 \\
\hline \multirow{2}{*}{ Axe } & \multirow{2}{*}{ Valeur propre } & \multirow{2}{*}{ Inertie $(\%)$} & Pseudo F & Statistique de Wilks & Degré de liberté & Probabilité \\
\hline 1 & 2,84 & 61,9 & 54,00 & 140,42 & 18 & 0,00 \\
2 & 1,29 & 28,1 & 24,55 & 66,39 & 10 & 0,00 \\
\hline
\end{tabular}

Tableau IV. Affectation des produits dans les différents groupes par analyse factorielle discriminante.

\begin{tabular}{lcccc}
\hline & \multicolumn{4}{c}{ Groupe d'affectation } \\
\cline { 2 - 5 } $\begin{array}{l}\text { Classification } \\
\text { a priori par ACP }\end{array}$ & $\begin{array}{c}\text { I } \\
\text { Engrais }\end{array}$ & $\begin{array}{c}\text { II } \\
\text { Amendements }\end{array}$ & $\begin{array}{c}\text { Produits riches } \\
\text { en fraction soluble } \\
\text { et hémicelluloses }\end{array}$ & $\begin{array}{c}\text { Produits riches } \\
\text { en matières } \\
\text { minérales }\end{array}$ \\
\hline Groupe I & $\mathbf{1 0}$ & $\mathbf{1}$ & - & 1 \\
Groupe II & - & $(6)$ & $\mathbf{2}$ & - \\
Groupe III & $\mathbf{1 2}$ & $(29-35)$ & - \\
Groupe IV & - & $\mathbf{2}$ & $\mathbf{8}$ & $\mathbf{2 3}$
\end{tabular}

Les chiffres en gras indiquent le nombre de produits et les chiffres entre parenthèses les numéros des produits qui changent de groupe.

raison de sa teneur forte en cellulose et lignine (respectivement 12,3 et $27,1 \%$ ). L'engrais organique $\mathrm{n}^{\circ} 22$ rejoint le groupe des produits riches en matières minérales, sa teneur en matières minérales étant de $45,2 \%$. Le fumier de bergerie frais $\left(n^{\circ} 29\right)$ et un amendement organique $\left(n^{\circ} 35\right)$ passent du groupe des amendements organiques aux produits riches en fraction soluble et hémicelluloses. Leurs compositions biochimiques confirment ce changement (annexe I). Le fumier de bergerie composté $\left(\mathrm{n}^{\circ} 30\right)$ et un amendement organique $\left(\mathrm{n}^{\circ} 31\right)$, initialement classés dans le groupe III, sont classés dans le groupe des amendements organiques; leurs compositions biochimiques confirment également ce changement de groupe. Un amendement organique $\left(\mathrm{n}^{\circ} 5\right)$ et un compost mixte $\left(\mathrm{n}^{\circ} 61\right)$, initialement classés dans le groupe des produits riches en matières minérales, sont classés dans le groupe des amendements organiques : leurs teneurs en matières minérales sont respectivement de 30,0 et $37,8 \%$.

La répartition des produits dans les quatre groupes, définis au cours de l'analyse en compo- santes principales, est validée en grande majorité par l'analyse discriminante (tableau V). La figure 4 présente le profil biochimique moyen des produits de chaque groupe défini précédemment.

\section{Devenir du carbone des produits et calcul du taux de carbone restant après décomposition (Tr)}

\section{Cinétique de minéralisation du carbone des différents produits testés}

La figure 5 présente la cinétique de minéralisation apparente du carbone des huit produits testés pendant les $40 \mathrm{j}$ d'incubation, calculée par différence entre le dégagement de $\mathrm{CO}_{2}$ du traitement avec produit et celui du sol seul. Par ce mode de calcul, on néglige une éventuelle extraminéralisation de la MO du sol (ou priming effect carboné) liée à l'apport des produits organiques. Les coefficients de variation moyens des mesures sont respective- 
Tableau V. Répartition des 61 produits dans les groupes définis par l'analyse en composantes principales et validés par analyse factorielle discriminante.

\section{Groupes de produits}

$n^{\circ}$ des produits

Groupe I :

Engrais organiques

$11-12-14-19-24-28-33-$

Groupe II :

Amendements organiques

Groupe III :

Produits riches en fraction

soluble et hémicelluloses

Groupe IV :

Produits riche

en matières minérales

\section{6-58-59}

2-3-5-8-23-30-31-34$35-36-37-38-39-43-49$ 60-61

6-9-10-16-18-20-27-29$32-44$

1-4-7-13-15-17-21-2225-26-40-41-42-45-4748-50-5 1-52-53-54-5556-57

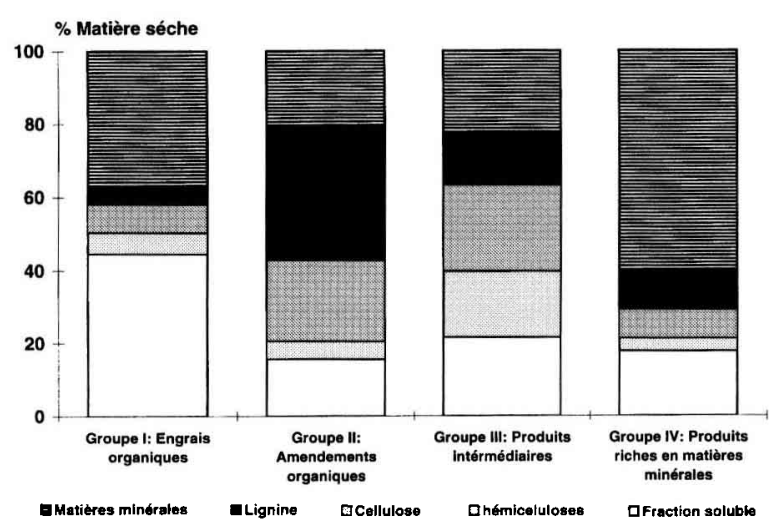

Fig 4. Composition biochimique (exprimée en fonction de la matière sèche) moyenne de chaque groupe de produits définie par l'analyse statistique (ACP et AFD).

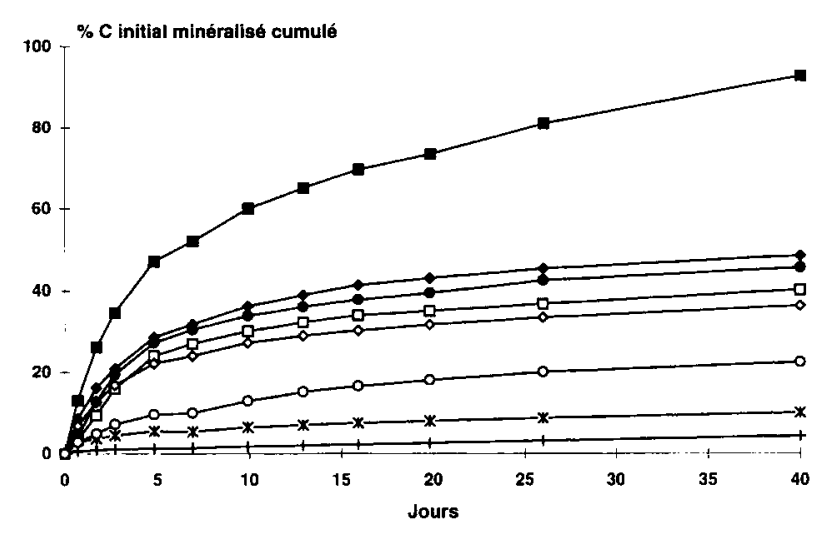

Fig 5. Cinétique de minéralisation cumulée du carbone, exprimé en \% C initial, mesuré au cours de l'incubation : $(\bullet)$ produit $n^{\circ} 11-(\square)$ produit $n^{\circ} 24-(*)$ produit $n^{\circ} 30-(+)$ produit $n^{\circ} 31-(\diamond)$ produit $n^{\circ} 4-(\square)$ produit $n^{\circ} 13-(\diamond)$ produit $n^{\circ} 16-(\bigcirc)$ produit $n^{\circ} 17$. ment de $2,2 \%\left(\mathrm{n}^{\circ} 11\right), 3,8 \%\left(\mathrm{n}^{\circ} 24\right), 16,0 \%$ $\left(\mathrm{n}^{\circ} 30\right), 11,9 \%\left(\mathrm{n}^{\circ} 31\right), 1,8 \%\left(\mathrm{n}^{\circ} 4\right), 5,6 \%$ $\left(\mathrm{n}^{\circ} 13\right), 10,7 \%\left(\mathrm{n}^{\circ} 17\right), 5,1 \%\left(\mathrm{n}^{\circ} 16\right)$ et de $17,8 \%$ pour le témoin sol. Les amendements organiques $\left(n^{\circ} 30\right.$ et 31$)$ se décomposent lentement : respectivement 10,0 et $4,5 \%$ du carbone apporté sont minéralisés au bout de 40 jours d'incubation. Les engrais organiques $\left(\mathrm{n}^{\circ} 11\right.$ et 24$)$ se décomposent rapidement dans le sol, respectivement 48,5 et $40.0 \%$ du carbone étant minéralisés en $40 \mathrm{j}$. La minéralisation du carbone des autres produits $\left(n^{\circ} 4,16\right.$ et 17$)$ est variable suivant les produits et comprise entre la minéralisation observée pour les engrais et celle mesurée pour les amendements, à $l^{\prime}$ 'exception du produit $\mathrm{n}^{\circ} 13$ qui se minéralise très rapidement : $93,0 \%$ du carbone initial est minéralisé au bout de $40 \mathrm{j}$.

\section{Modélisation de la quantité de carbone restant dans le sol au cours de la décomposition}

Des modèles exponentiels $\left(\operatorname{Tr}=a \cdot e^{b r}\right)$ ou logarithmiques ( $\operatorname{Tr}=a+b$.Logt), utilisés pour des expérimentations de longue durée et pour définir différents compartiments du produit ayant une biodégradabilité différente, peuvent décrire de façon satisfaisante la quantité de carbone restant d'un produit en cours de décomposition dans le sol au cours du temps. En raison de la faible durée de l'incubation $(40 \mathrm{j})$ et du faible nombre de points expérimentaux, le choix s'est porté sur un modèle de type puissance. Ainsi, la quantité de carbone restant dans le sol au cours de l'incubation, mesurée indirectement par le dioxyde de carbone dégagé, peut être estimée par le modèle suivant :

$$
\mathrm{T} r=a . t^{b}
$$

avec $\mathrm{T} r=$ proportion de carbone restant dans le sol, $t$ le temps, en jours, et $a$ et $b$, deux constantes spécifiques pour chaque produit.

Un ajustement des données (onze mesures réalisées pendant l'incubation) a été réalisé en transformant le modèle puissance en une relation linéaire de la façon suivante :

$$
\begin{aligned}
\operatorname{Tr} & =a \cdot t^{b} \\
\Leftrightarrow \quad \log \operatorname{T} r & =a^{\prime}+b \cdot \log t \\
\text { avec } a^{\prime} & =\log a
\end{aligned}
$$

Le tableau VI indique la valeur des paramètres $a$ ' et $b$ calculés pour chaque produit ainsi que le coefficient de corrélation $r$ pour chaque ajustement. Les ajustements réalisés sont satisfaisants pour les produits testés à l'exception de l'amendement organique $n^{\circ} 31$ où une grande variabilité des quantités de $\mathrm{CO}_{2}$ dégagé et une minéralisation 
Tableau VI. Coefficients $a^{\prime}$ et $b$ et écarts types correspondants $\left(\sigma a^{\prime}\right.$ et $\sigma b$ ), coefficients de corrélation $r$, écart type résiduel $\left(\sigma^{2}\right)$ et $\%$ de C restant après 30 ans calculés au cours des ajustements des données respirométriques au modèle puissance pour les huit produits organominéraux testés en incubation.

\begin{tabular}{|c|c|c|c|c|c|c|c|}
\hline $\begin{array}{l}n^{\circ} \\
\text { produit }\end{array}$ & $\begin{array}{l}\text { Coefficient } \\
\mathrm{a}^{\prime}=\log \mathrm{a}\end{array}$ & $\sigma \mathrm{a}$ & $\begin{array}{c}\text { Coefficient } \\
\mathbf{b}\end{array}$ & $\sigma \mathbf{b}$ & $\begin{array}{c}\text { Coefficient } \\
\mathrm{r}\end{array}$ & $\sigma^{2}$ & $\begin{array}{l}\% \text { C restant } \\
\text { après } 30 \text { ans }\end{array}$ \\
\hline 11 & $-0,1497$ & 0,0042 & $-0,1096$ & 0,0098 & 0,996 & 0,0024 & $22,3 \pm 1,1$ \\
\hline 24 & $-0,1241$ & 0,0038 & $-0,0644$ & 0,0089 & 0,996 & 0,0020 & $29,6 \pm 1,3$ \\
\hline 30 & $-0,0185$ & 0,0013 & $-0,0286$ & 0,0031 & 0,976 & 0,0002 & $81,8 \pm 1,2$ \\
\hline 31 & $-0,0081$ & 0,0014 & $-0,0034$ & 0,0032 & 0,892 & 0,0002 & $92,5 \pm 1,5$ \\
\hline 4 & $-0,0959$ & 0,0015 & $-0,0954$ & 0,0035 & 0,999 & 0,0003 & $37,3 \pm 0,6$ \\
\hline 13 & $-0,5149$ & 0,0846 & 0,0369 & 0,1980 & 0,897 & 0,9870 & $0,9 \pm 0,5$ \\
\hline 17 & $-0,0575$ & 0,0042 & $-0,0222$ & 0,0100 & 0,976 & 0,0025 & $57,3 \pm 2,7$ \\
\hline 16 & $-0,1431$ & 0,0026 & $-0,0819$ & 0,0060 & 0,998 & 0,0009 & $24,3 \pm 0,7$ \\
\hline
\end{tabular}

faible du carbone pendant la période étudiée expliquent le moins bon coefficient de corrélation $(r=0,89)$ calculé pour ce produit. Le coefficient de corrélation $r$ entre valeurs mesurées et estimées est également plus faible pour le produit $n^{\circ} 13$. Ce produit se minéralise très rapidement $(93 \% \mathrm{C}$ apporté) au cours des $40 \mathrm{j}$ d'incubation.

Cet ajustement du taux de carbone restant au cours du temps permet d'estimer le carbone restant après une grande période et donc d'estimer la proportion d'humus stable formé après décomposition du produit. Le tableau VI présente ces résultats calculés suivant les ajustements précédents. L'estimation du carbone restant est faite au bout de 30 années après l'apport des matières organiques. Pour le produit $n^{\circ} 31$, le modèle simule une très faible perte de carbone au bout de 30 ans. En effet, $92 \%$ du carbone apporté serait présent dans le sol au bout de 30 ans. Pour le produit $n^{\circ} 13$ qui est rapidement décomposé dans le sol (fig 5), la quantité de carbone restant dans le sol après 30 années serait très faible (moins de $1 \%$ ) mais tout à fait compatible avec la décomposition très rapide de ce produit, malgré la plus faible qualité de l'ajustement des données mesurées.

Relation entre le taux de carbone restant dans le sol à long terme ( $\mathbf{T r}$ ) et la composition biochimique et la classification des produits

\section{Prévision de la proportion de matière organique restant dans le sol à long terme (Tr) en fonction de la constitution biochimique des produits organominéraux}

Un ajustement linéaire multiple a été réalisé pour estimer la proportion de carbone restant dans le sol d'un produit organominéral (coefficient $\mathrm{Tr}$ ) en fonction de sa composition biochimique. La variable expliquée est le taux de carbone restant à long terme exprimé en \% de la matière organique des huit produits étudiés. Les variables explicatives sont les pourcentages respectifs de chaque fraction biochimique de ces produits déterminée par la méthode de Van Soest et Wine (1963) et exprimée par rapport à la matière sèche du produit. L'expression des différentes fractions biochimiques en fonction de la matière sèche du produit permet d'intégrer un éventuel effet de la fraction minérale sur le processus d'humification.

L'ajustement linéaire multiple obtenu est le suivant :

$$
\begin{aligned}
\operatorname{Tr} & =(0,3221 * \% \text { Fr. soluble })-(0,7155 * \% \text { hémicelluloses }) \\
& +(0,6717 * \% \text { cellulose })+(1,8919 * \% \text { lignine }) \\
& +(0,0271 * \% \text { mat. minérales }) \\
& \quad r=0,998
\end{aligned}
$$

Proportion de matière organique restant dans le sol à long terme pour l'ensemble des produits organominéraux analysés

L'annexe 1 et la figure 6 présentent les résultats de l'estimation du coefficient $\mathrm{Tr}$ exprimé par rapport à la matière organique selon la relation [3] définie précédemment. La relation [3] aboutit à une estimation a priori cohérente du taux de M.O. stable après décomposition (comprise entre 0 et $100 \%$ de la MO initiale) pour l'ensemble des produits testés à l'exception du produit $\mathrm{n}^{\circ} 38(\mathrm{~T} r=1,21)$. La relation [3] n'est plus valable pour ce produit $n^{\circ} 38$ car celui-ci possède une composition biochimique qui sort de la gamme testée au cours de l'étude respirométrique. En effet, la teneur en lignine de ce produit est supérieure à celle de l'amendement le plus 
stable (produit $\mathrm{n}^{\circ} 31$ ) étudiée en respirométrie. Bien que la gamme des produits étudiés en respirométrie soit la plus large possible (de 4,5 à 93,0\% de $C$ restant après $40 \mathrm{j}$ d'incubation), le taux de MO stable après décomposition du produit $n^{\circ} 38$ ne peut être estimée par la relation [3] en raison de sa forte teneur en lignine.

\section{Relation entre classification statistique des produits et coefficient $\operatorname{Tr}$ (taux de carbone stable après décomposition)}

La figure 7 présente les taux de MO stable après décomposition calculés par la relation [3] pour l'ensemble des produits classés par groupe et

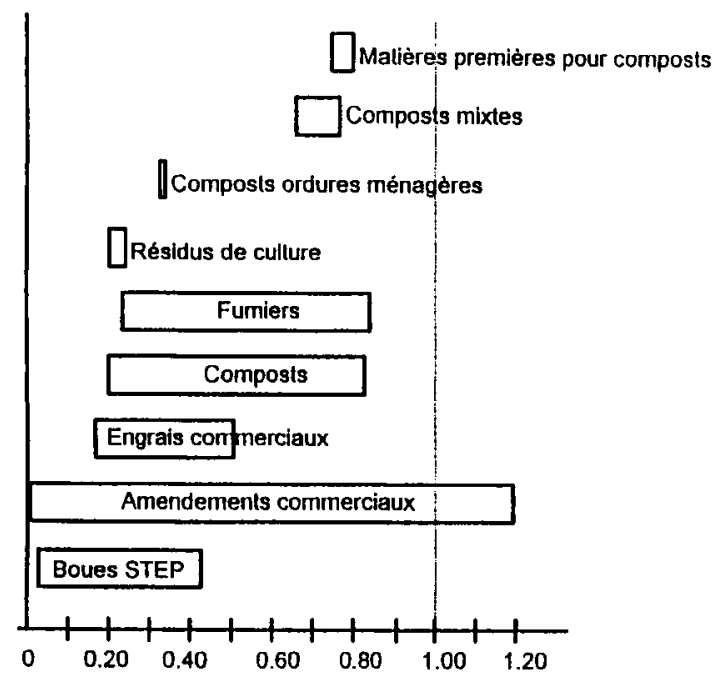

Fig 6. Taux de MO stable après décomposition pour les différents catégories de produits organominéraux estimé suivant la relation [3]. exprimés par rapport à la matière sèche du produit : un coefficient égal à 0,5 signifie que $50 \%$ du produit sec reste sous forme d'humus dans le sol après décomposition. Les produits appartenant au groupe des engrais organiques (groupe I) possèdent un taux de MO stable faible compris entre 0 (produit $n^{\circ} 22$ ) et $34 \%$ (produit $n^{\circ} 19$ ). Les produits appartenant au groupe des amendements (groupe II) présentent des taux élevés compris entre $42 \%$ pour le produit $n^{\circ} 35$ et $111 \%$ pour le produit $n^{\circ} 38$. Les produits appartenant au groupe III possèdent des taux variables suivant la nature des produits : $1 \%$ pour l'amendement commercial $\mathrm{n}^{\circ} 20$ et $78 \%$ pour les pulpes de raisins $\left(\mathrm{n}^{\circ} 32\right)$. Les produits appartenant au groupe IV (riches en matières minérales) possèdent des taux faibles inférieurs à $35 \%$.

L'estimation du taux de MO stable par cette méthode est cohérente avec la définition des groupes réalisés par l'analyse statistique des données. Il est donc possible d'après l'analyse biochimique, de classer le produit en groupe suivant l'usage agronomique de celui-ci : engrais, amendement, matières premières pour composts ou produits riches en minéraux et d'estimer le taux de carbone stable après décomposition dans le sol.

\section{DISCUSSION}

La littérature précisant la valeur humique de produits organominéraux connus confirme l'estimation réalisée dans ce travail du taux de MO stable

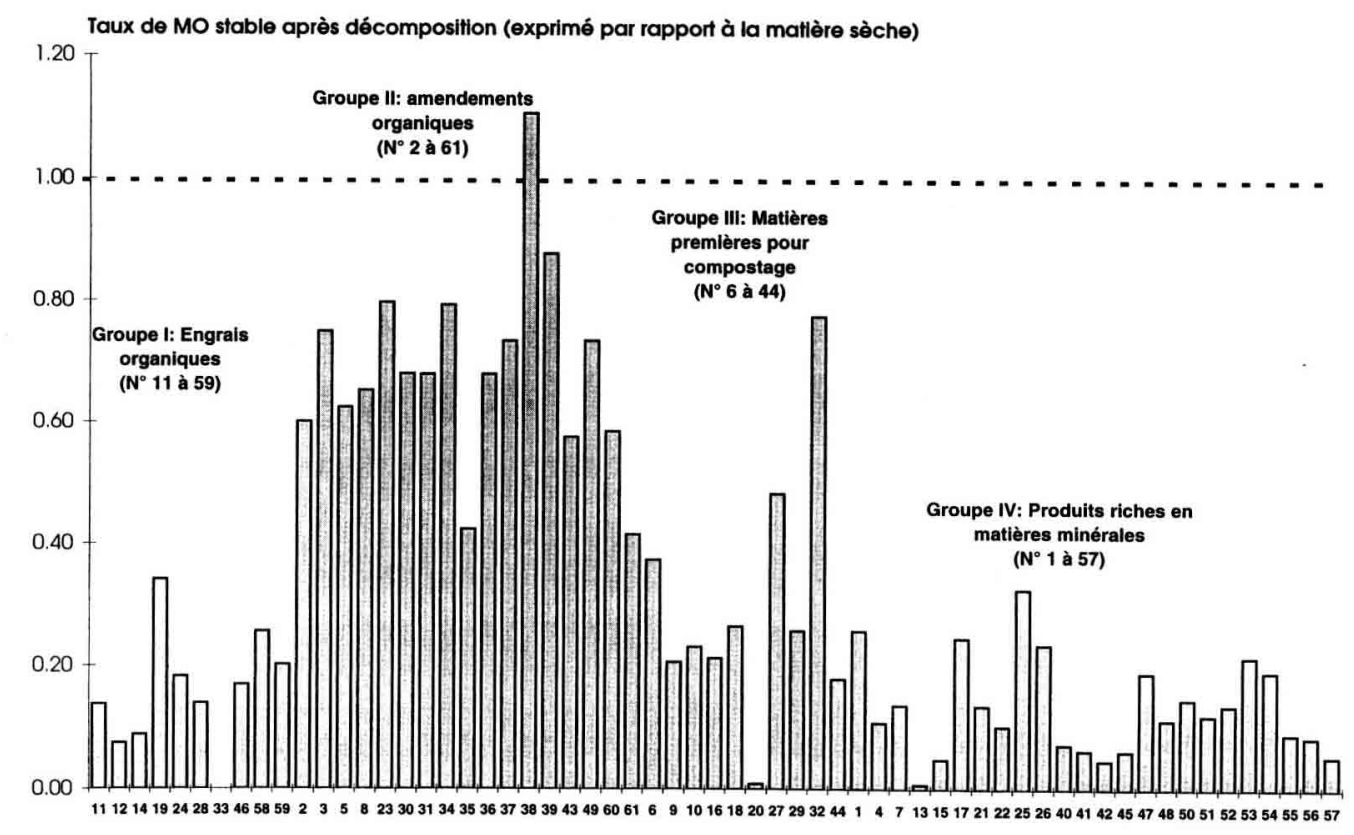

Fig 7. Taux de MO stable après décomposition exprimé par rapport à la matière sèche pour chaque groupe de produit. 
après décomposition. Les boues de station d'épuration possèdent un coefficient $\mathrm{k} l$ peu élevé de l'ordre de 0 à 0,20 suivant les auteurs (Rémy et Marin-Laflèche, 1976; Gomez et al, 1984; Boiffin et al, 1986). Le coefficient $\mathrm{T} r$ exprimé par rapport à la matière organique des boues de station étudiées dans cette étude $\left(\mathrm{n}^{\circ} 1,11,12,13,14,15\right.$, $45,46,57,58,59)$ varie de 0,03 (boue $\mathrm{n}^{\circ} 13$ ) à 0,44 (boue $\mathrm{n}^{\circ} 1$ ). Les résidus de culture (tiges de maïs et blé) possèdent également un coefficient $\mathrm{k} 1$ faible de l'ordre de 0,05 à 0,20 suivant Lubet et Juste (1979), Delas et Molot (1983), Boiffin et al (1986) et Rémy et Marin-Laflèche (1976). Suivant la relation [3], l'estimation du coefficient $\mathrm{T} r$ de ces deux résidus de culture ( $\mathrm{n}^{\circ} 9$ et 10$)$ est de respectivement 0,21 et 0,24 . Le coefficient $\mathrm{kl}$ du fumier de champignonnière (produit $\mathrm{n}^{\circ} 7$ ) est estimé à 0,30 (Boiffin et al, 1986). Suivant la relation [3], le coefficient $\mathrm{T} r$ est de 0,27. Les travaux de Delas et Molot (1983) estiment le coefficient isohumique d'un fumier de ferme frais à 0,32. L'estimation du taux de MO stable de ce type de produits par la relation [3] est de 0,33 pour le fumier de bergerie frais $\left(\mathrm{n}^{\circ} 29\right)$ et de 0,26 pour le fumier de bovin frais $\left(\mathrm{n}^{\circ} 44\right)$.

Par le traitement statistique des données (ACP et AFD), la classification agronomique des produits organominéraux semble plus aisée par caractérisation biochimique que la seule utilisation du rapport $\mathrm{C} / \mathrm{N}$. Les $\mathrm{C} / \mathrm{N}$ moyens sont différents pour les quatre groupes considérés (tableau VII). Cependant, d'après les minima et maxima, ils couvrent un large spectre et il n'est pas possible de définir l'appartenance à un groupe suivant ce seul rapport $\mathrm{C} / \mathrm{N}$. Le rapport $\mathrm{C} / \mathrm{N}$ n'est donc pas un critère fiable pour définir l'usage agricole d'un produit organominéral inconnu.

Suivant la relation établie entre composition biochimique et $\operatorname{Tr}$ (relation [3]), les matières minérales ont un rôle positif sur l'humification. Ceci confirme l'hypothèse de ce travail sur le rôle

Tableau VII. Teneurs en $\mathrm{C}$ et $\mathrm{N}$ moyennes, rapports $\mathrm{C} / \mathrm{N}$ moyens, minimums et maximums des produits appartenant à chaque groupe statistique.

$\begin{array}{lccccc}\text { Groupe } & \begin{array}{c}\text { Teneur } C \\ \text { moyenne } \\ (\%)\end{array} & \begin{array}{c}\text { Teneur } N \\ \text { moyenne } \\ (\%)\end{array} & \begin{array}{c}\text { Rapport } \\ \text { C/N } \\ \text { moyen }\end{array} & \begin{array}{c}\text { Rapport } \\ \text { C/N }\end{array} & \begin{array}{c}\text { Rapport } \\ \text { minimum }\end{array} \\ \text { minimum }\end{array}$

de « protection » des matières minérales constitutives d'un produit sur sa décomposition et son humification. De même, on note le rôle positif de la lignine sur le taux d'humification d'un produit dans le sol. En effet, cette fraction est constituée de molécules ayant une structure chimique très proche des molécules organiques constituant l'humus du sol (Dommergues et Mangenot, 1970 ; Swift et al, 1979; Monties, 1980). Cet effet a été également observé par Djakovitch (1988). Les travaux d'Andriulo (1995) confirment la corrélation entre le pourcentage de matière organique restant dans le sol à long terme estimée par traçage isotopique et la teneur en lignine des différents résidus végétaux étudiés dans son travail.

Le coefficient $\mathrm{T} r$, est une estimation du coefficient isohumique kl défini par Hénin et Dupuis (1945). En effet, le calcul de ce coefficient Tr est basé sur des mesures respirométriques et l'analyse des fractions biochimiques d'un produit organique. Il est délicat d'affirmer que ce coefficient est le coefficient isohumique $\mathrm{kl}$ qui ne peut être accessible que par des expérimentations de terrain de longue durée (Hénin et Dupuis, 1945) et/ou l'emploi du traçage isotopique ${ }^{13} \mathrm{C}$ ou ${ }^{14} \mathrm{C}$ (Jenkinson et Rayner, 1977 ; Van Veen et Paul, 1981 ; Balesdent et Balabane, 1992). Ce coefficient $\mathrm{T} r$ reste cependant une bonne estimation du coefficient isohumique $\mathrm{kl}$ en raison de la cohérence entre la composition biochimique, les mesures respirométriques réalisées au cours de ce travail et le taux d'humification mesuré réellement pour quelques produits organominéraux connus.

La corrélation établie au cours de l'étude statistique entre teneur en matières minérales et teneur en carbone total peut être un outil de vérification au laboratoire de la cohérence de ces deux mesures faites indépendamment. La relation entre ces deux paramètres est alors :

$\% \mathrm{C}$ total $=47,82-0,387 *$ (\% matières minérales $)$

Il est important de signaler que les différentes fractions dénommées fraction soluble, hémicelluloses, cellulose et lignine ne correspondent pas à des composés biochimiques purs et clairement définis : cette technique de fractionnement biochimique définit en réalité des fractions caractérisées par leur solubilité avec un réactif approprié : eau chaude et sodium lauryl sulfate pour la fraction soluble, cethyltriméthylammonium bromide pour la fraction hémicellulosique, acide sulfurique $72 \%$ pour la fraction cellulosique (le complément organique étant défini comme la lignine). Cependant, cette analyse, relativement simple à mettre en œuvre au laboratoire, permet d'estimer 
la proportion de matière organique restant dans le sol à long terme. Il peut constituer une analyse de routine des produits organominéraux utilisables en agriculture pour préciser leur utilisation agronomique : amendements ou engrais organiques. En effet, devant la multiplicité des produits organominéraux, en particulier les déchets de l'activité humaine et industrielle recyclés en agriculture et se caractérisant souvent par une forte charge minérale, cet outil de laboratoire permet une approche rapide et rationnelle de leur utilisation agricole avec un risque d'erreur moindre que le rapport $\mathrm{C} / \mathrm{N}$ et évite la mise en place d'expérimentations longues et coûteuses.

Dans l'avenir, une amélioration de cette classification pourrait être réalisée par un traitement statistique d'analyses chimiques et biochimiques d'un nouveau panel de produits organominéraux. Ces analyses supplémentaires permettraient de mieux connaître les différents groupes et améliorer leurs caractéristiques définis dans ce travail. De la même manière, des études respirométriques complémentaires pourraient ajuster au mieux la relation définie dans ce travail. En effet, en raison de la faible durée de l'incubation réalisée, cette modélisation apparaît moins précise pour les amendements organiques qui se décomposent lentement dans le sol. Pour estimer avec une meilleure précision le taux de MO restant dans le sol après décomposition de ce type de produits, il sera nécessaire d'affiner les résultats par des incubations de plus longue durée pour estimer avec plus de précision ce coefficient.

Cependant, les teneurs des différentes fractions biochimiques sont des variables souvent nécessaires aux modèles mathématiques simulant les biotransformations de l'azote et du carbone dans le sol (Mac Gill et al, 1980 ; Rao et al, 1981 ; Molina et al, 1983 ; Van Veen et al, 1985). Ces mesures des fractions biochimiques peuvent être le point de départ d'une estimation de la cinétique de minéralisation ou d'organisation de l'azote minéral après incorporation d'un produit organominéral dans le sol en fonction des facteurs du milieu.

Ces différents éléments montrent l'intérêt agronomique de cette méthode d'analyse de laboratoire pour une meilleure connaissance et une utilisation rationnelle des produits organominéraux en agriculture.

\section{REMERCIEMENTS}

L'auteur remercie F Papirer, JP Birling et A Jamot pour la mise au point et la réalisation pratique des analyses biochimiques et des mesures respirométriques ainsi que D Collin pour son aide pour l'interprétation statistique des données.

\section{RÉFÉRENCES}

Andriulo A (1995) Modélisation de l'évolution des matières organiques des sols de la Pampa. Relation avec les systèmes de culture. Thèse doctorat Ina-PG, $143 \mathrm{p}+$ annexes

Allison FE (1955) Does nitrogen applied to crop residues produce more humus? Soil Sci Soc Am Proc 19, 210-211

Balesdent J, Balabane M (1992) Maize root derived soil organic carbon estimated by natural ${ }^{13} \mathrm{C}$ abundance. Soil Biol Biochem 24, 97-101

Boiffin J, Keli Zagbalhi J, Sebilotte M (1986) Systèmes de culture et statut organique des sols dans le Noyonnais: application du modèle de HéninDupuis. agronomie 6, 437-446

Boulaine J (1995) Quatre siècles de fertilisation. Étude de la gestion des sols 2, 3, 201-208

Comité d'orientation pour la réduction des pollution des eaux par les nitrates (Corpen) (1991). Code de bonne pratique agricole. Directive $91 / 676 / C E E d u$ 12 décembre 1991

Delas J, Molot C (1983) Effets de différents amendements organiques sur le rendement du maïs et de la pomme de terre cultivés en sol. agronomie 3, 19-26

Delphin JE, Conesa AP (1979) Évolution de la matière organique du sol d'un essai rotation, irrigation, restitution des pailles dans la plaine de la Hardt. Ann Agron 30, 179-189

Djakovitch JL (1988) Mise au point d'une méthode de détermination rapide du coefficient isohumique de matériaux utilisables pour l'amendement des sols. Diplôme d'ingénieur du Cnam, Bordeaux, 208 p

Dommergues Y, Mangenot F (1970) Écologie microbienne du sol. Masson, Paris

Fog K (1988) The effect of added nitrogen on the rate of decomposition of organic matter. Biol Rev 63, 433-462

Gomez A, Lineres M, Tauzin J, Solda P, Juste C. (1984) Étude de l'incidence de boues de station d'épuration à des sols sableux sur l'évolution qualitative et quantitative de la matières organiques de ces sols. Convention d'étude station d'agronomie Inra Bordeaux secrétariat d'État à l'Environnement $n^{\circ} 81-285$

Hassink J (1994) Effect of soil texture and grassland management on soil organic $\mathrm{C}$ and $\mathrm{N}$ rate of $\mathrm{c}$ and $\mathrm{N}$ mineralization. Soil Biol Biochem 25, 533-538

Hénin S, Dupuis M (1945) Essai de bilan de la matière organique du sol. Ann Agron (nouvelle série) 3, 17 29 
Hénin S, Monnier G, Turc L (1959) Un aspect de la dynamique des matières organiques du sol. CR Acad Agric Fr 248, 138-141

Jenkinson DS, Rayner JH (1977) The turnover of the organic matter in some of the Rothamsted classical experiments. Soil Sci 123, 298-305

Jensen HL (1929) On the influence of the carbon: nitrogen ratios of organic material on the mineralization of nitrogen. J Agric Sci 19, 71-82

Lineres M, Djakovitch JL (1993) Caractérisation de la stabilité biologique des apports organiques par l'analyse biochimique. Matières organiques et agriculture. Quatrièmes journées de l'analyse de terre (Gemas). Cinquième forum de la fertilisation raisonnée (Comifer). 16 - 18 novembre 1993 (Decroux et Ignazi, éd), 159-168

Lubet E, Juste C (1979) Effet de l'incorporation d'une prairie temporaire, d'un engrais vert et de l'exportation des résidus de récolte sur les moncultures de maiis implantées dans les sols sablo-limoneux du sud des Landes. CR Acad Agric Fr 4, 295-309

Mac Gill WB, Hunt HW, Woodmansee RG, Reuss JO (1980) Phoenix, a model of the dynamics of carbon and nitrogen in grasslands soils. Ecol Bull 33, 49115

Martin JP, Filip Z, Haider (1976) Effect of montmorillonite and humate on growth and metabolic activity of some actino-mycetes. Soil Biol Biochem 8, 409-413

Mary B (1987) Effets du précédant cultural sur la disponibilité du sol en azote minéral. CR Acad Agric Fr $73,57-69$

Mary B, Fresneau C, Morel JL, Mariotti A (1993) C and $\mathrm{N}$ cycling during decomposition of roots mucilage, root and glucose in soil. Soil Biol Biochem 25, 1005-1014

Molina JE, Clapp CE, Scheffer MJ, Chichester FW, Larson WE (1983) NCSOIL, a model of nitrogen and carbon transformation in soil: description, calibration and behaviour. Soil Sci Am J 47, 85-91

Monties B (1980) Les polymères végétaux. Polymères pariétaux et alimentaires non azotés. GauthierVillars, Paris
Morel R (1968) Évolution de l'azote et du carbone organique du sol au cours d'une expérience de longue durée. Ann Agron 19, 153-174

Morel R, Richer A, Masson P (1956) Étude expérimentale de la variation du taux de matière organique dans le champ d'expérience de Grignon. Ann Agron $7,183-194$

Rao PSC, Davidson JM, Jessup RE (1980) Simulation of nitrogen behaviour in the root zone of crop land areas receiving organic wastes. In: Simulation of nitrogen behaviour soil-plants systems. Pudoc, Wageningen

Recous S, Robin D, Darwis D, Mary B (1995) Soil inorganic $N$ availability : effect on maize residue decomposition. Soil Biol Biochem 27, 1529-1538

Rémy JC, Marin-Laflèche A (1976) L'entretien organique des terres. Entreprises Agricoles 84, 3-7

Robin D (1994) Effet de la disponibilité de l'azote sur les flux bruts de carbone et d'azote au cours de la décomposition des résidus végétaux dans les sols. Thèse doctorat Ina-PG, $201 \mathrm{p}+$ annexes

Swift MJ, Heal OW, Anderson MJ (1979) Decomposition in Terrestrial Ecosystems. Blackwell Scientific Publications, Oxford

Thomas B, Amstrong DG (1949) A study of some methods at present used for the determination of lignin. J Agric Sci 39, 328-334

Van Soest PJ (1949) Use of detergents in analysis of fibrous feeds. III. Study of effects of heating and drying on yield of fiber and lignin in forages. $J$ Agric Sci 39, 335-346

Van Soest PJ, Wine RH (1963) Use of detergents in the analysis of fibrous feeds. VI. Determination of plant cell constituents. J Off Chem 50, 50-55

Van Veen JA, Paul EA (1981) Organic carbon dynamics in grassland soils. I. Background information and computer simulation. Can J Soil Sci 61, 185-201

Van Veen JA, Ladd JN, Friessel J (1985) Modelling C and $\mathrm{N}$ turnover through the microbial biomass in soil. Plant Soil 76, 257-274

Waksman SA (1924) Influence of microorganisms upon the carbon-nitrogen ratio in soil. J Agric Sci 14, 555-562 